\title{
Internal structure of Longmenshan fault zone at Hongkou outcrop, Sichuan, China, that caused the 2008 Wenchuan earthquake*
}

\author{
Tetsuhiro Togo ${ }^{1, \uparrow}$ Toshihiko Shimamoto ${ }^{2} \quad$ Shengli Ma \\ Xueze $\mathrm{Wen}^{3}$ and Honglin $\mathrm{He}^{2}$ \\ ${ }^{1}$ Department of Earth and Planetary Systems Science, Graduate School of Science, Hiroshima \\ University, Higashi-Hiroshima, 739-8526, Japan \\ 2 State Key Laboratory of Earthquake Dynamics, Institute of Geology, China Earthquake \\ Administration, Beijing 100029, China \\ ${ }^{3}$ Earthquake Administration of Sichuan Province, Chengdu 610041, China
}

\begin{abstract}
This paper reports the internal structures of the Beichuan fault zone of Longmenshan fault system that caused the 2008 Wenchuan earthquake, at an outcrop in Hongkou, Sichuan province, China. Present work is a part of comprehensive project of Institute of Geology, China Earthquake Administration, trying to understand deformation processes in Longmenshan fault zones and eventually to reproduce Wenchuan earthquake by modeling based on measured mechanical and transport properties. Outcrop studies could be integrated with those performed on samples recovered from fault zone drilling, during the Wenchuan Earthquake Fault Scientific Drilling (WFSD) Project, to understand along-fault and depth variation of fault zone properties. The hanging wall side of the fault zone consists of weakly-foliated, clayey fault gouge of about $1 \mathrm{~m}$ in width and of several fault breccia zones of $30-40 \mathrm{~m}$ in total width. We could not find any pseudotachylite at this outcrop. Displacement during the Wenchuan earthquake is highly localized within the fault gouge layer along narrower slipping-zones of about 10 to $20 \mathrm{~mm}$ in width. This is an important constraint for analyzing thermal pressurization, an important dynamic weakening mechanism of faults. Overlapping patterns of striations on slickenside surface suggest that seismic slip at a given time occurred in even narrower zone of a few to several millimeters, so that localization of deformation must have occurred within a slipping zone during coseismic fault motion. Fault breccia zones are bounded by thin black gouge layers containing amorphous carbon. Fault gouge contains illite and chlorite minerals, but not smectite. Clayey fault gouge next to coseismic slipping zone also contains amorphous carbon and small amounts of graphite. The structural observations and mineralogical data obtained from outcrop exposures of the fault zone of the Wenchuan earthquake can be compared with those obtained from the WFSD-1 and WFSD-2 boreholes, which have been drilled very close to the Hongkou outcrop. The presence of carbon and graphite, observed next to the slipping-zone, may affect the mechanical properties of the fault and also provide useful information about coseismic chemical changes.
\end{abstract}

Key words: Wenchuan earthquake; Longmenshan fault system; Beichuan fault; fault rock; fault mechanics; fault-zone structure; amorphous carbon; graphite

CLC number: P315.8 Document code: A

\section{Introduction}

The Wenchuan earthquake (12 May 2008, $\left.M_{\mathrm{W}} 7.9\right)$

\footnotetext{
* Received 25 January 2011; accepted in revised form 4 April 2011; published 10 June 2011.

† Corresponding author. e-mail: duketogotetsu@gmail.com

(c) The Seismological Society of China and Springer-Verlag Berlin Heidelberg 2011
}

caused disastrous damages, but it also stimulated numerous work on geological and geophysical aspects of this earthquake such as coseismic slip as deduced from surface ruptures and GPS/InSAR data, earthquake disasters, earthquake rupture propagation and strong motion, and active faults and tectonic framework of the southwestern margin of Tibetan Plateau. Two special issues were published (Yin et al., 2010; Klinger et al., 
2010a), and Yin (2010) and Klinger et al. (2010b) gave concise summary of 57 papers in the issues covering wide disciplines. On the other hand, Chinese government launched the Wenchuan Earthquake Fault Scientific Drilling (WFSD) Project under the leadership of Academician Zhiqin $\mathrm{Xu}$, and preliminary results were reported at a session of Fall Annual Meeting of American Geophysical Union ( $\mathrm{Xu}$ and $\mathrm{Li}, 2010$; Li et al., 2010b; and others). Drilling into fault zones following a big earthquake started after the 1995 Kobe earthquake (or Hyogo-Ken-Nanbu earthquake) to promote the understanding of the fault zone that caused the earthquake (see Oshiman et al., 2001, a special issue summarizing most work done in the Nojima Fault Probe Project). Nojima Fault Probe Project was followed by Taiwan Chelungpu-fault Drilling Project (TCDP), drilling into the fault that caused the 1999 Taiwan Chi-Chi earthquake (Ma et al., 2006; Song et al., 2007; among many others). WFSD project is the third case in the world of drilling into fault zones (Longmenshan fault system) that caused a large earthquake. Importance of faultzone drilling projects, immediately after large/great earthquakes, was discussed fully at an international continental scientific drilling program workshop (see a report by Brodsky et al., 2009).

One of the most important, but difficult, tasks in fault-zone drilling projects is to simulate the earthquake that just occurred based on measured mechanical and transport properties of fault zones. Mechanical and transport properties of Chelungpu fault zones were measured using shallow drill cores, samples from surface outcrops and TCDP drill cores (Tanikawa and Shimamoto, 2009; Sone and Shimamoto, 2009). Noda and Lapusta (2009) included those properties for northern and southern parts of Chelungpu fault in their earthquake-cycle modeling and reproduced the difference in fault behavior between the northern and the southern portions, respectively (e.g., Ma et al., 2003). The difference in fault motion is largely due to the difference in permeability, that is, northern fault zone has lower permeability by one to two orders of magnitude than the southern fault zone, making thermal pressurization more effective in the north (see Sibson, 1973; Wibberley and Shimamoto, 2005; Noda and Shimamoto, 2005; Rice, 2006). This could have caused more dynamic weakening of Chelungpu fault in the north, resulting in larger slip, dominance of low-frequency ground motion (and less damage) and longer recurrence interval of earthquakes in the north than in the south (Noda and Lapusta, 2009). Reproducing earthquakes based on measured fault properties are becoming possible now although properties of deeper part of Chelungpu fault are not determined as yet.

Institute of Geology, China Earthquake Administration (CEA), has started an integrated fault and earthquake project as a part of WFSD project, aiming at reproducing Wenchuan earthquake based on measured fault properties of fault zones constituting the Longmenshan fault system at the boundary of Tibetan Plateau and Sichuan Basin. In order to achieve such a challenging target, the following three steps of work are needed: (1) to study fault-zones in drill cores and at surface outcrops to delineate deformation and chemical and fluid-flow processes at shallow to deep portions of faults, (2) to reproduce intrafault processes in laboratory experiments and determine mechanical and transport properties of faults, and (3) to reproduce the earthquake by modeling based on measured properties including realistic fault geometry. It is of paramoun$\mathrm{t}$ importance to conduct outcrop studies of the faultzone because they provide extensive information about along-fault and depth variation of the geometries and mechanical/transport properties of fault zones, which can be compared and integrated with punctual information on fault zones obtained by drill cores (see Han et al., 2010; Yang et al., 2010).

This paper reports internal structures, textures and major constituent minerals of Beichuan-Yingxiu fault zone at an outcrop at Bajiaomiao in Hongkou, Sichuan province, China (see Burchfiel et al. (2008) for tectonic framework and see Xu et al. (2009) for surface ruptures associated with Wenchuan fault). Togo et al. (2011) reports results from high-velocity friction experiments reproducing seismic fault motion. BeichuanYingxiu fault in Hongkou formed in Triassic sandstone and shale not so far from the basement granite and Proterozoic Pengguan massif that thrust over the sedimentary sequences (see geological maps with surface ruptures in Liu-Zeng et al., 2010). Thus present work will yield useful data for the internal structures (this paper) and mechanical properties (Togo et al., 2011) of the Longmenshan fault system at shallow depths in sedimentary sequences near its western end.

The present work is also particularly relevant to the WFSD Project as the first drill hole (WFSD-1) was drilled underneath the studied fault outcrop, from a place which is only several hundred meters to the north (Xu and Li, 2010; Li et al., 2010b). The borehole intercepted the fault zone, which is interpreted to have hosted the coseismic slip during the Wenchuan earth- 
quake, at a depth of about $590 \mathrm{~m}$. Furthermore, the second drilling (WFSD-2) is being conducted now to penetrate a deeper part of the fault at a nearby locality. The two boreholes will allow the depth variation of the fault zone properties to be examined and compared with those obtained from fault outcrop studies. The comparison between physical properties of fault zones at the surface and at a depth is important as properties measured from surface outcrops may be affected by weathering processes.

\section{Geological setting: the Beichuan fault}

Two major surface ruptures associated with Wenchuan earthquake have been recognized along Beichuan fault (or Beichuan-Yingxiu fault) and Hanwang fault (or Pengguan fault) in Longmenshan fault system. Xu et al. (2009), Lin et al. (2009) and Liu-Zeng et al. (2009) reported coseismic displacements along these ruptures. Yin (2010) compiled their results in their Figure 3 showing reasonable agreements. Shen et al. (2009) and $\mathrm{Xu}$ et al. (2010) determined coseismic slip from GPS and InSAR data, and their results are compared with surface-rupture data of Xu et al. (2009) in Figure 6 of $\mathrm{Xu}$ et al. (2010), also showing reasonable agreements. Xu et al. (2008) reported that the maximum vertical displacement is about $6.2 \pm 0.5 \mathrm{~m}$ near Shenxigou in southwest part and $6.5 \pm 0.5 \mathrm{~m}$ near the Beichuan in northwest part along the Yingxiu-Beichuan rupture zone (Figure 1). However, recent studies indicate that the maximum co-seismic displacement is $10 \pm 0.5 \mathrm{~m}$ at a place northeast of Beichuan (Li et al., 2010a; Fu et al., 2011).

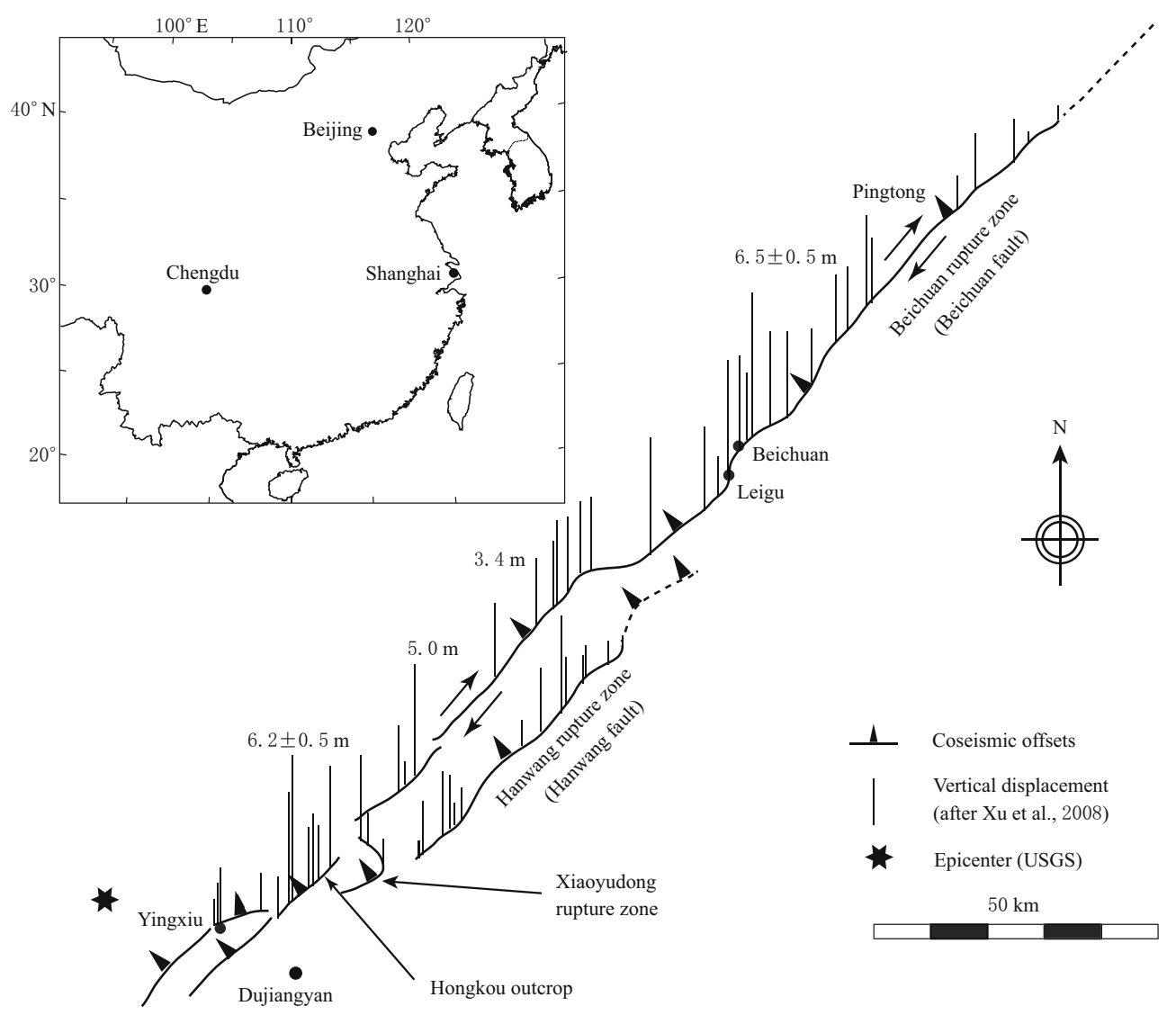

Figure 1 Location of the Hongkou outcrop of Beichuan fault, plotted on a surface rupture map with coseismic vertical displacement after Xu et al. (2009). 
Different names have been used for those faults in the literatures; we will use Beichuan fault and Hanwang fault following $\mathrm{Xu}$ et al. (2009). Overall, thrust motion is predominant for Hanwang fault to the south (about $100 \mathrm{~km}$ long) and oblique slip (thrust and right-lateral slip) occurred along Beichuan fault (about $270 \mathrm{~km}$ long; reported length varies from $240 \mathrm{~km}$ to $285 \mathrm{~km}$ among workers). Two asperities are recognized in Hongkou area to the southwest and in Beichuan near the center of the fault, with maximum total displacement of 5 to $8 \mathrm{~m}$ (Figure 6 of $\mathrm{Xu}$ et al., 2010). The Hongkou outcrop is located in the Hongkou asperity (see its location in Figure 1).
A clear fault scarp formed at Bajiaomiao in Hongkou (Figure 2a, position $B$ in Figure 3 ) during Wenchuan earthquake. Liu-Zeng et al. (2010) reported vertical offset of 4 to 5 meters at the nearby fault scarp (locality 193 in Table A1 of their paper). A coseismic fault with slickenside surface with striations (Figures $2 \mathrm{~b}$ and $2 \mathrm{c}$ ) formed at position $C$ in Figure 3 , about 10 $\mathrm{m}$ to the southwest from the fault scarp. The very flat fault surface in Figure 2b has a strike of $\mathrm{N} 32^{\circ} \mathrm{E}$ and a dip of $76^{\circ} \mathrm{NW}$. Whereas Li et al. (2010b) pointed out that a fault at the depth of $590 \mathrm{~m}$ in the WFSD-1 is a candidate for the coseismic fault during Wenchuan earthquake because there are a small temperature
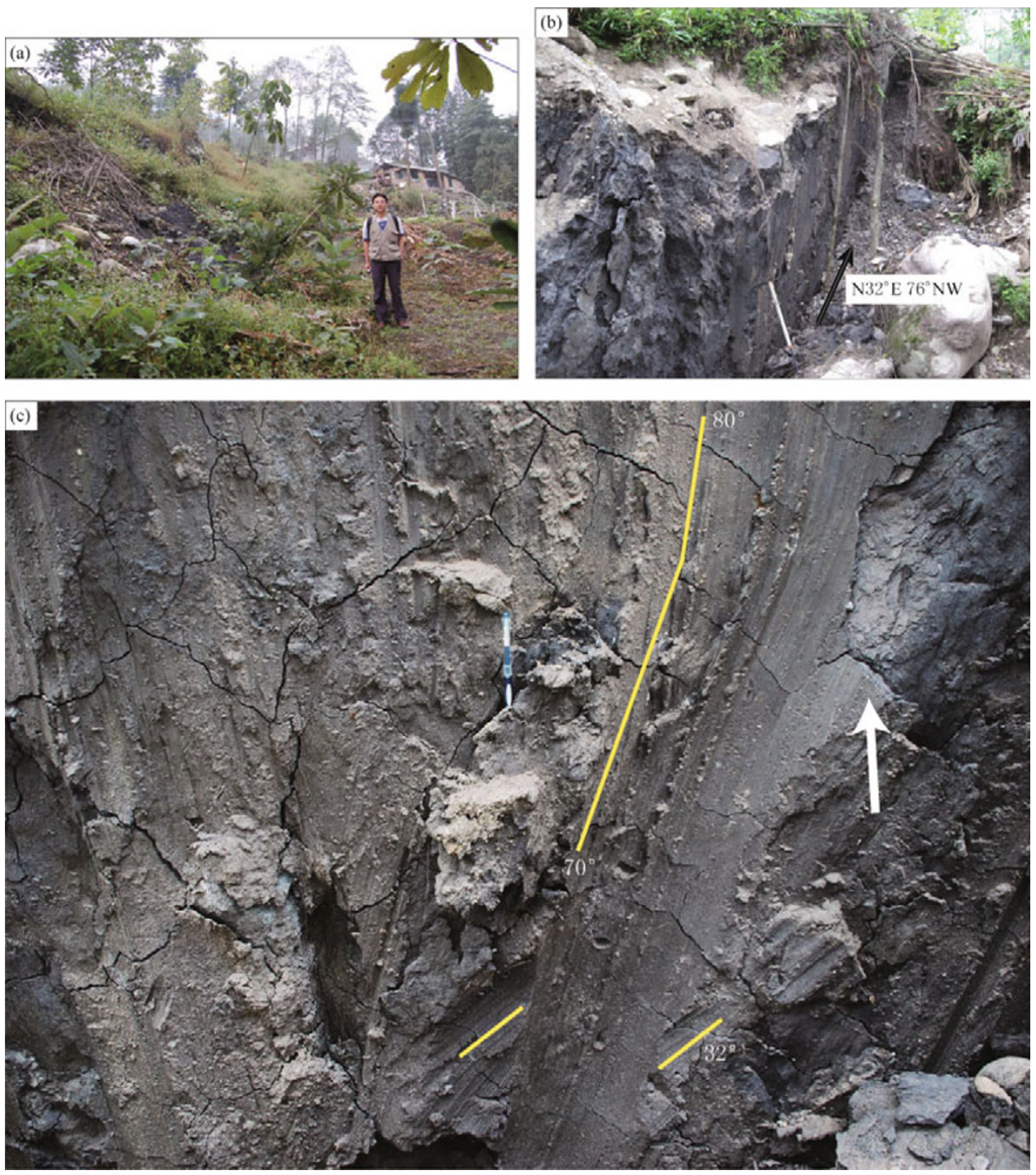

Figure 2 Surface ruptures along Beichuan fault in Bajiaomiao in Hongkou, about several hundred meters to the south of WFSD-1 drilling site (GPS location of Hongkou outcrop $\left(31^{\circ} 08^{\prime} 42.2^{\prime \prime} \mathrm{N}, 103^{\circ} 41^{\prime} 29.8^{\prime \prime} \mathrm{E}\right)$ ). (a) Fault scarp with a man $(1.6 \mathrm{~m}$ tall $)$ as a scale. (b) A fault surface with slickenside surface striking $\mathrm{N} 32^{\circ} \mathrm{E}$ and dipping $76^{\circ} \mathrm{NW}$. (c) A close-up of the central part of previous photo showing overlapping striations. 


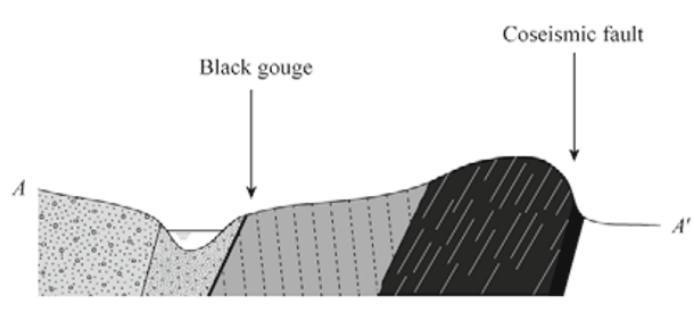

- Weakly-foliated clayey fault gouge (fg)

VI/ Black fault breccia (bfb)

Weakly deformed fault breccia (wdfb)

W.2. Grayish fine breccia (gfb)

Grayish breccia (gb)

- Black gouge

$\leftarrow$ cliff

D) Slope failure
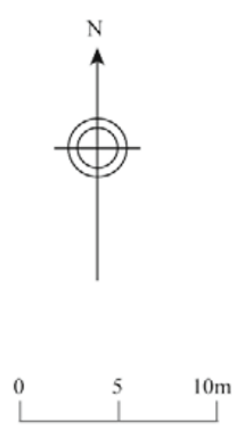

\section{(1)}
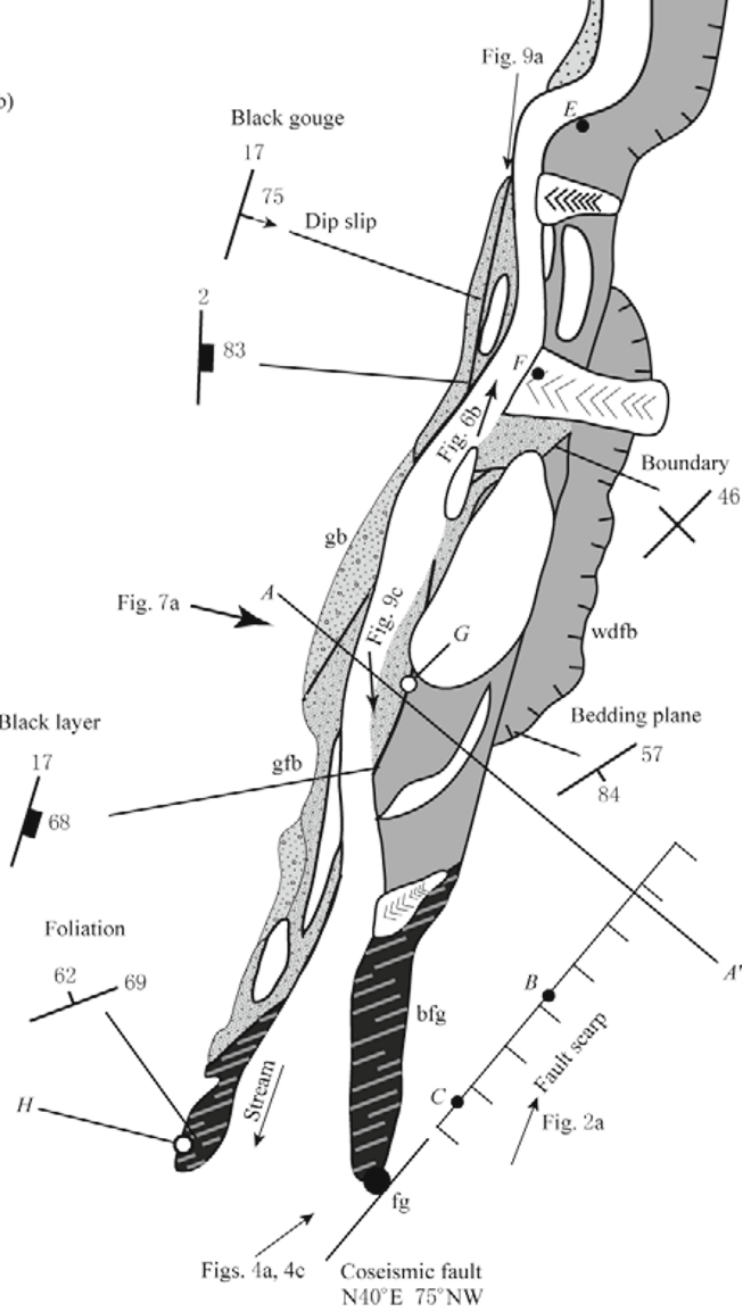

Figure 3 A route map and a cross-section $A-A^{\prime}$ of the Beichuan fault zone in the Longmenshan fault system at Bajiaomiao in Hongkou area, Sichuan province, China. The main stream of Baisha River runs through the fault outcrop to the south. Surface ruptures associated with Wenchuan earthquake formed next to the southeastern part of the fault outcrop. A cross section along the line $A-A^{\prime}$ is drawn perpendicular to the coseismic surface rupture. Marker positions and the direction of the photographs and sketches are indicated with symbols and arrows.

anomaly and anomalies in clay mineralogy and in magnetic susceptibility. This position in the drill core connected with the coseismic fault on the surface gives the dip angle of the fault as NW62 . Thus the Beichuan fault at and near Hongkou outcrop is a fairly high-angle fault.

Alluvial deposits along Baisha River were washed away by a debris flow during the summer of 2009, leaving about 80-m-long good outcrop of Beichuan fault zone on the hanging wall side. This was a rare chance 
to see the scale and internal structures of the Beichuan fault zone and we described the outcrop in October 2009 (Figure 3). When we visited this outcrop in September 2008, fault core containing clayey fault gouge of $0.7 \mathrm{~m}$ in width was exposed as shown in Figures $4 \mathrm{a}$ and $4 \mathrm{~b}$ (fault gouge was approximately at position fg in Figure 3 ). This exposure is buried in debris now and Figure 4c shows a view of the same location in October 2009 with a new exposure of fault breccia. Overall, the fault zone mostly consists of fault breccias, which we conventionally classified into four types (Figure 3 ) because their appearance is somewhat different and they are separat- ed mostly by small-scale faults containing thin black gouge. The fault breccias lenses are bounded by smallscale faults containing thin layers of black gouge.

Sandstone rocks, which display almost no deformation, crop out at position $D$ in Figure 3 and we consider it as the margin of the fault zone. The strike of foliation of fault gouge is $\mathrm{N} 30^{\circ}-40^{\circ} \mathrm{E}$ (Figure $4 \mathrm{~b}$ ) and this is consistent with the strike of slickenside surface $\left(\mathrm{N} 32^{\circ} \mathrm{E}\right)$ of coseismic fault in Figure $2 \mathrm{~b}$. The fault-zone width on the hanging-wall side is $30-40$ meters wide if one takes $\mathrm{N} 30^{\circ}-40^{\circ} \mathrm{E}$ as the strike of the fault zone (see the scale and orientation of fault in Figure 3). On the other hand,
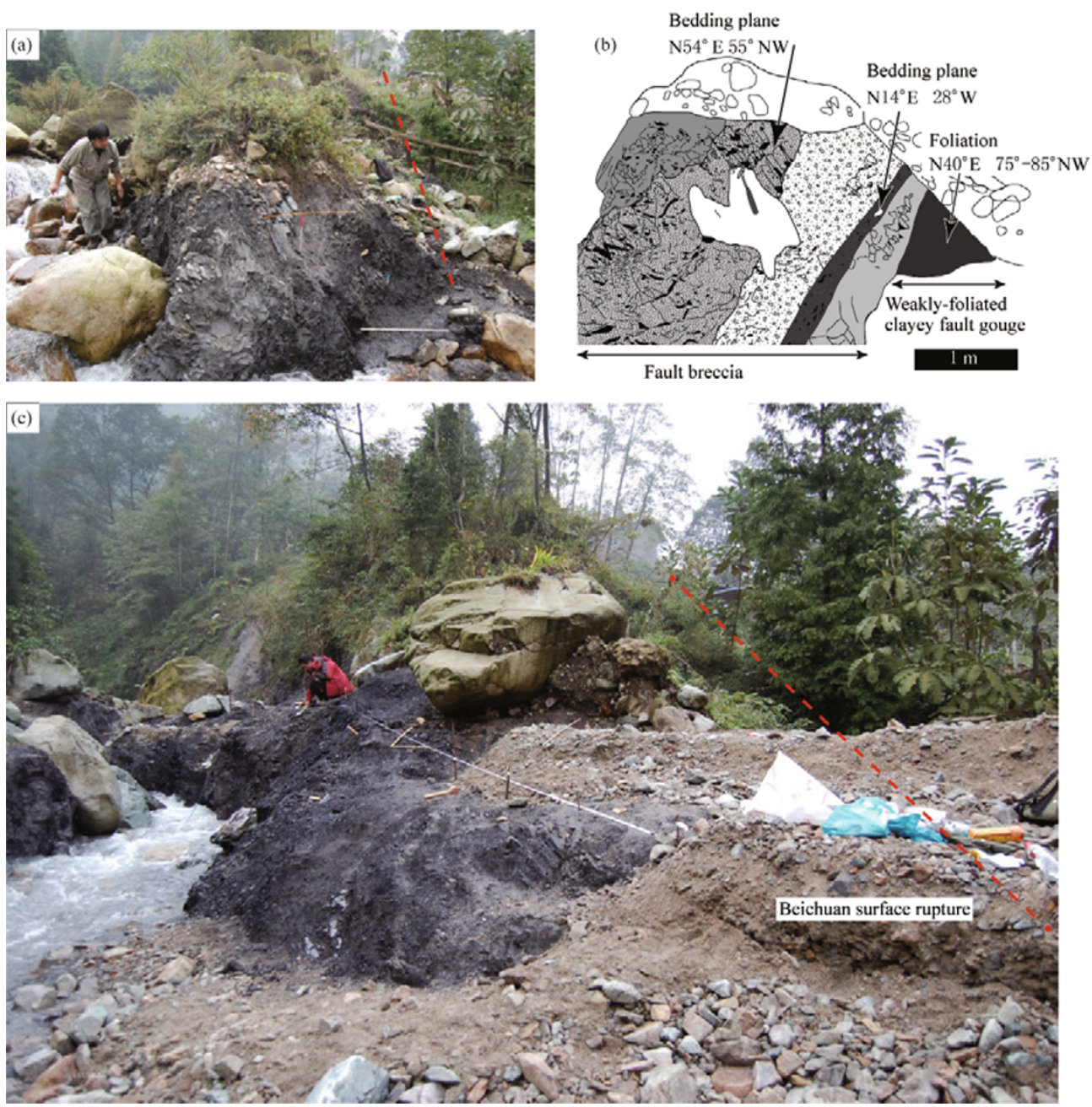

Figure 4 Fault core part of the Beichuan fault zone in Hongkou. (a) A photograph of an exposure of fault core part and (b) its sketch showing internal structures of fault zone. The photograph was taken in September 2009, about four months after the Wenchuan earthquake. (c) A slightly wider view of the same place taken in October 2009 after debris flow washed away the outcrop and burying the exposure in (a). Southwestward extension of surface rupture is drawn as dashed lines. Fault rock on the left side of (c) is black fault breccia. 
the general trend of surface rupture at Bajiaomiao of Hongkou is around $\mathrm{N} 55^{\circ} \mathrm{E}$ (Figure 3e of Liu-Zeng et al., 2010), and this gives the fault-zone width of about $60 \mathrm{~m}$. However, we consider 30 to 40 meters wide fault zone on the hanging wall side, consisting mostly of fault breccias, as a reasonable estimate because the fault surface in Figure $2 \mathrm{~b}$ and foliation in gouge are likely to represent the orientation of fault at and near this outcrop, rather than the general trend of the fault.

\section{Fault core structure and slip- ping zone of the Wenchuan earthquake}

The remarkable fault scarp in Figures $2 \mathrm{~b}$ and $2 \mathrm{c}$ collapsed soon after the earthquake and two trees fell down with this collapse (see the upper-right corner of Figure 4a). When the authors did field work on this outcrop in September 2008, an outcrop shown in Figures $4 \mathrm{a}$ and $4 \mathrm{~b}$ was the only exposure to see fault core consisting of clayey, weakly-foliated fault gouge of about $0.7 \mathrm{~m}$ in width. We follow fault-rock classification of Sibson (1977) with a modification to include foliated fault gouge. Strike and dip of the foliation in gouge are $\mathrm{N} 40^{\circ} \mathrm{E}$ and $80^{\circ} \mathrm{NW}$, respectively. From fault gouge to the northwest, fault zone consists of a fault breccia zone $(0.3 \mathrm{~m}$ wide), pelitic fault breccia zone $(0.2 \mathrm{~m})$, light-colored psammitic fault breccia $(0.5-1.0 \mathrm{~m})$, grayish psammitic fault breccia zone (1-2 m) and black fault breccia (Figures 4a and 4b). Those breccias have lithology and foliation reflecting original sedimentary rocks and their bedding planes. These and other fault breccias at this outcrop are mostly foliated, but we do not call those "foliated fault breccia" since the foliation did not form by deformation alone.

The exposure in Figures 4a and 4b was located several meters to the southwest of the surface rupture with slickenside surface in Figure 2b. Southwestward extension of the fault scarp, shown as dashed lines in Figures $4 \mathrm{a}$ and $4 \mathrm{c}$, and careful comparison of Figures $2 \mathrm{~b}$ and $4 \mathrm{a}$ indicates that the coseismic fault cuts near the edge of the gouge zone in Figures $4 \mathrm{a}$ and $4 \mathrm{~b}$. The gouge zone may be slightly wider and may be of about $1 \mathrm{~m}$ in width because the location of the coseismic fault may not coincide with the edge of the foliated clayey gouge zone in Figures $4 \mathrm{a}$ and $4 \mathrm{~b}$. Fault gouge zone of about the same width can be recognized behind the slickenside surface (see the left-half of Figure 2b) although the boundary between gouge and fault breccia cannot be seen on the photograph. Fault breccia was exposed after the fault surface in Figure 2b collapsed by about $1 \mathrm{~m}$ in width. We thus conclude that fault gouge is of about $1 \mathrm{~m}$ thick.

Weak foliation in clayey fault gouge has been observed at the meso- (Figure 5a) and micro-scale (Figure 5b). High-magnification photomicrographs reveal that foliation is developed due to preferred orientation of platy minerals (Figures 5c and 5d). Weak and heterogeneous development of foliation suggests that it is formed by deformation, rather than original sedimentary structures.

Impressive striations are reported from the fault surface at this outcrop by He et al. (2008) and Wen et al. (2010). Figure 2c is a photograph which exhibits overprinting striations of at least three sets of directions. Liu-Zeng et al. (2010) not only discussed kinematic$\mathrm{s}$ of fault motion from the curved and overprinting striations, but also comprehensively reviewed relevant literature on similar striations and on modeling of dynamic fault motion that might have created such striations. This issue will not be discussed here. However, we will focus on another aspect of the slickenside surface.

A controversial issue in fault mechanics in last several years is the slipping zone width, i.e., how thick is the zone that accommodates fault displacement during an earthquake. This width determines if frictional work during seismic fault motion is dissipated in a narrow zone or over a broad zone and can have large effect on mechanical properties of fault, as will be discussed in the final section. One can see cross section where slickenside surface is peeled off (e.g., an arrowed point in the upper-right corner of Figure 2c). Intensely sheared zone is observed in places to be 10 to $20 \mathrm{~mm}$ in thickness (Figure 2), indicating that the overall slipping zone on the hanging-wall side is of that order. Overlapping striations are complex on the left-half of Figure 2c, but steeply-plunging striations undoubtedly overprinted the gently-plunging striations at the lower-center of the photograph (see striation annotated by yellow lines with plunges in Figure 2c). This overprinting feature clearly indicates that fault motion leaving the striations did not involve with the bulk shearing of slipping zone. Shearing of a few to several-millimeters in width appears to be involved with coseismic fault motion at a given time. Deformation is likely to localize within a slipping zone even during a single earthquake. 

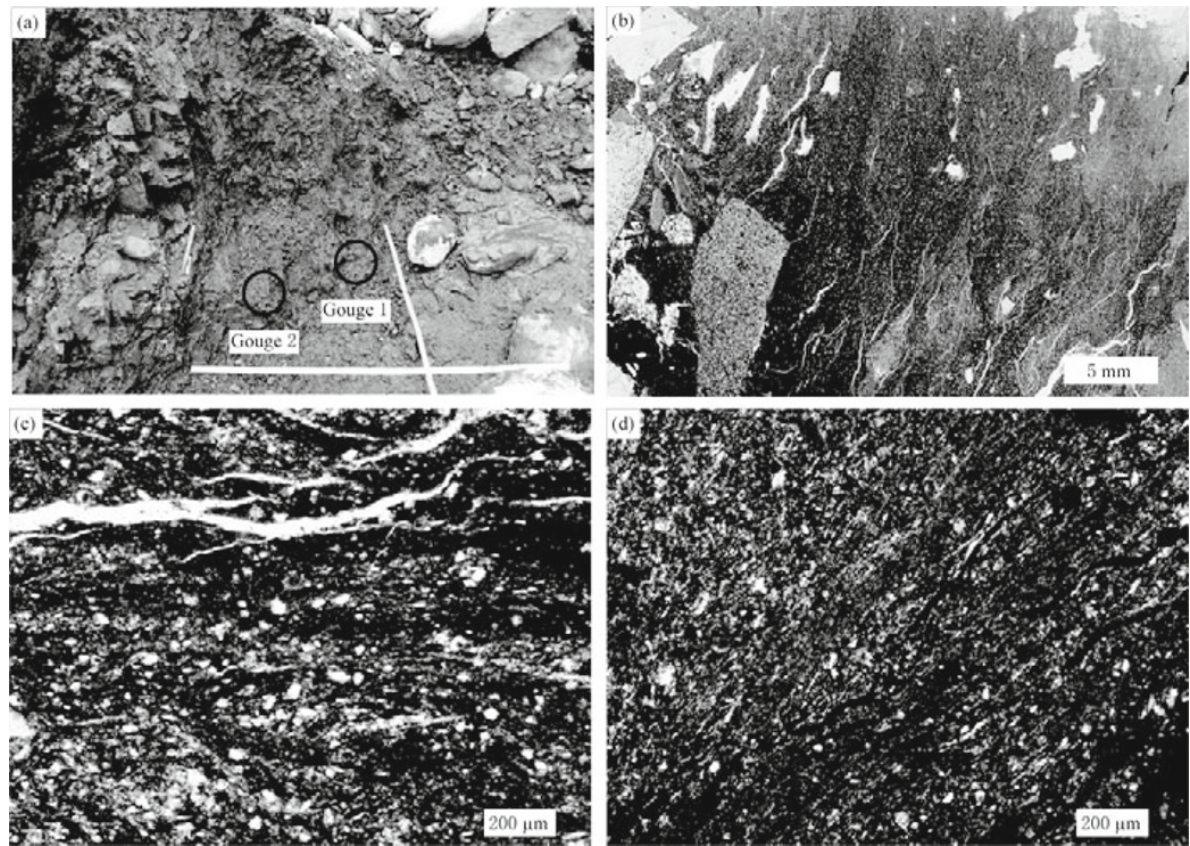

Figure 5 (a) A close-up photograph of weakly-foliated clayey fault gouge in Figure 4a. (b) A scanned image of a thin section of weakly-foliated clayey fault gouge. (c, d) Photomicrographs of the same thin section showing foliation in horizontal direction and in the upper-right to lower-left direction, respectively. All photomicrographs were taken under plane polarized light. Foliation is formed by preferred orientation of platy minerals. Open circles in (a) give locations of gouge samples 1 and 2 used for experiments in Togo et al. (2011). Gouge sample 1 was used for making a thin section shown in (b) to (d).
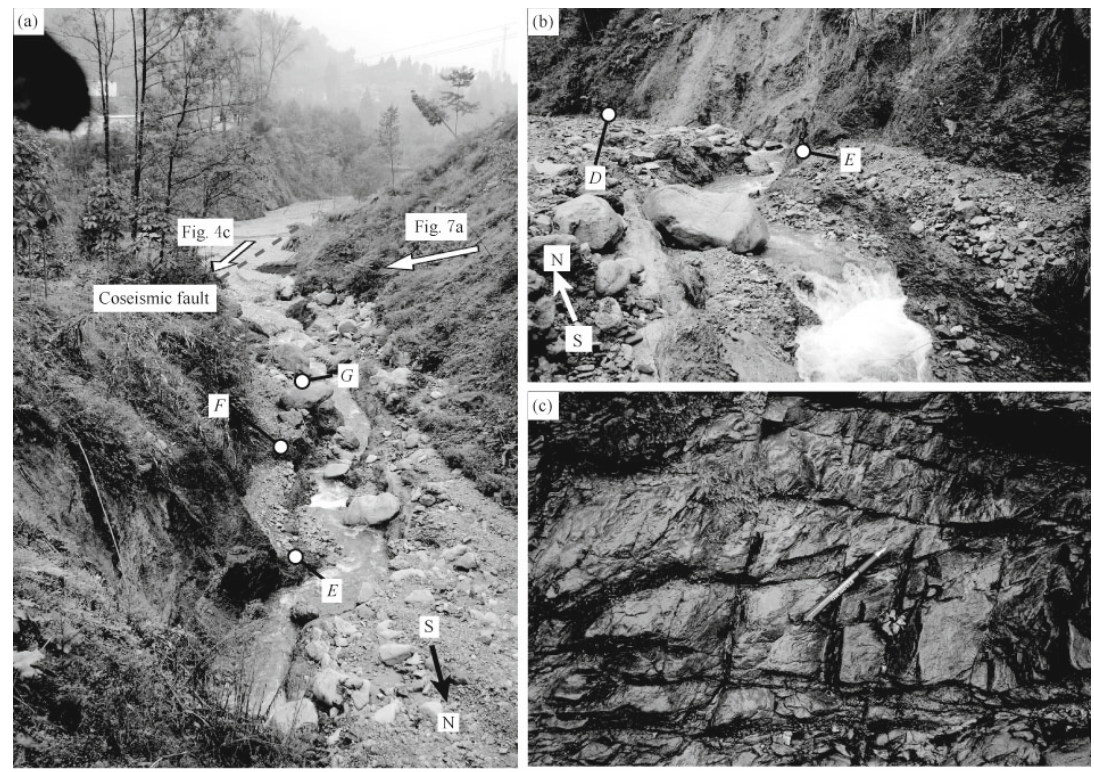

Figure 6 (a) Panoramic photograph of the Hongkou outcrop of the Beichuan fault zone, viewing SSW direction toward the surface rupture shown in dashed line. (b) A photograph from the middle fault-breccia zone taken to NNE towards the host-rock boundary. (c) Fractured sandstone as the host rock at the northern end (position $D$ in Figure 3). Total length of the exposure along Baisha River is approximately $85 \mathrm{~m} \mathrm{long.}$ Photographs were taken in October 2009. D, E, F and $G$ refer to positions in Figure 3. 


\section{Fault breccia zones and black gouge containing amorphous carbon}

Figures $6 \mathrm{a}$ and $6 \mathrm{~b}$ give overviews of exposures of fault breccia zones in October 2009 after a debris flow in the summer of the same year. This portion of Baisha
River was covered with big boulders before the debris flow. The photograph (a) was taken in SSW direction towards the coseismic fault shown in dashed line, and (b) was taken in the opposite direction from near the center of the breccia zones. Fault rocks shown in Figure 3 include exposures along the stream and on cliffs. Figure $6 c$ exhibits jointed sandstone with almost no brecciation (no clast-matrix structures) at position $D$
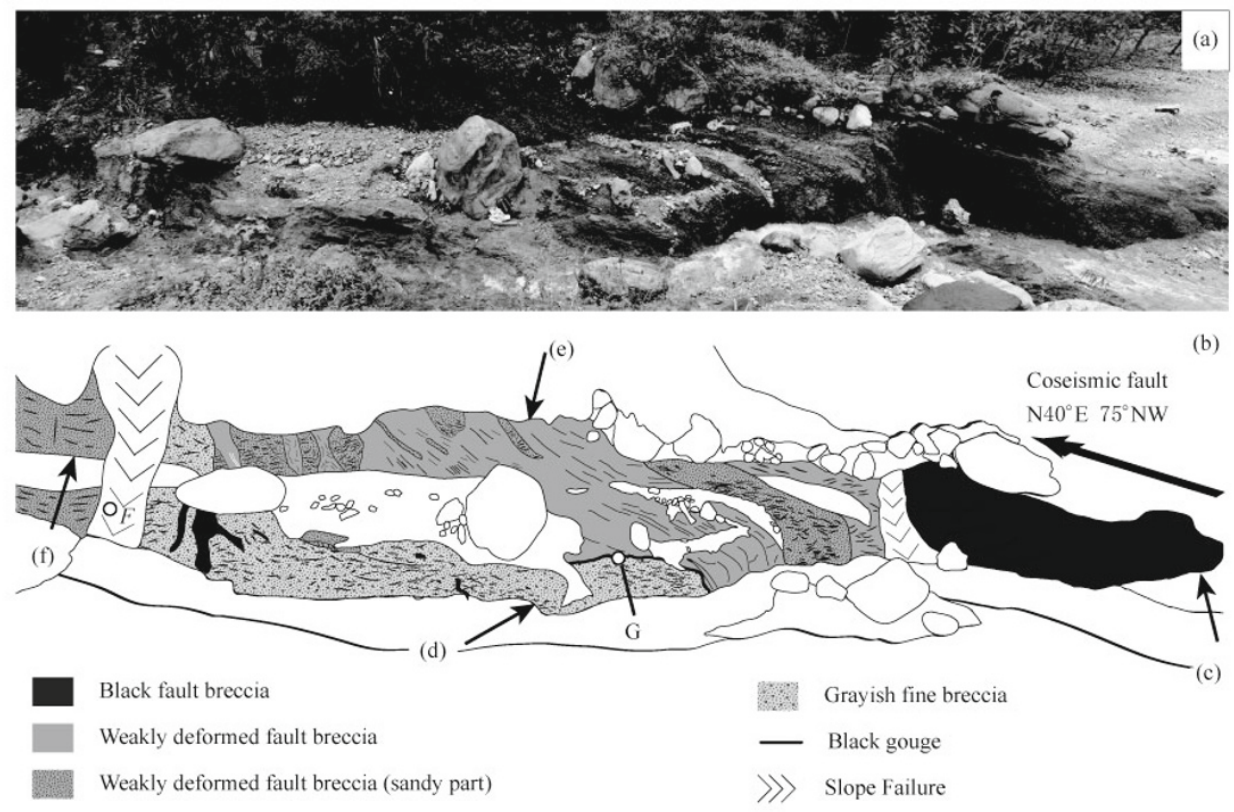

(b)
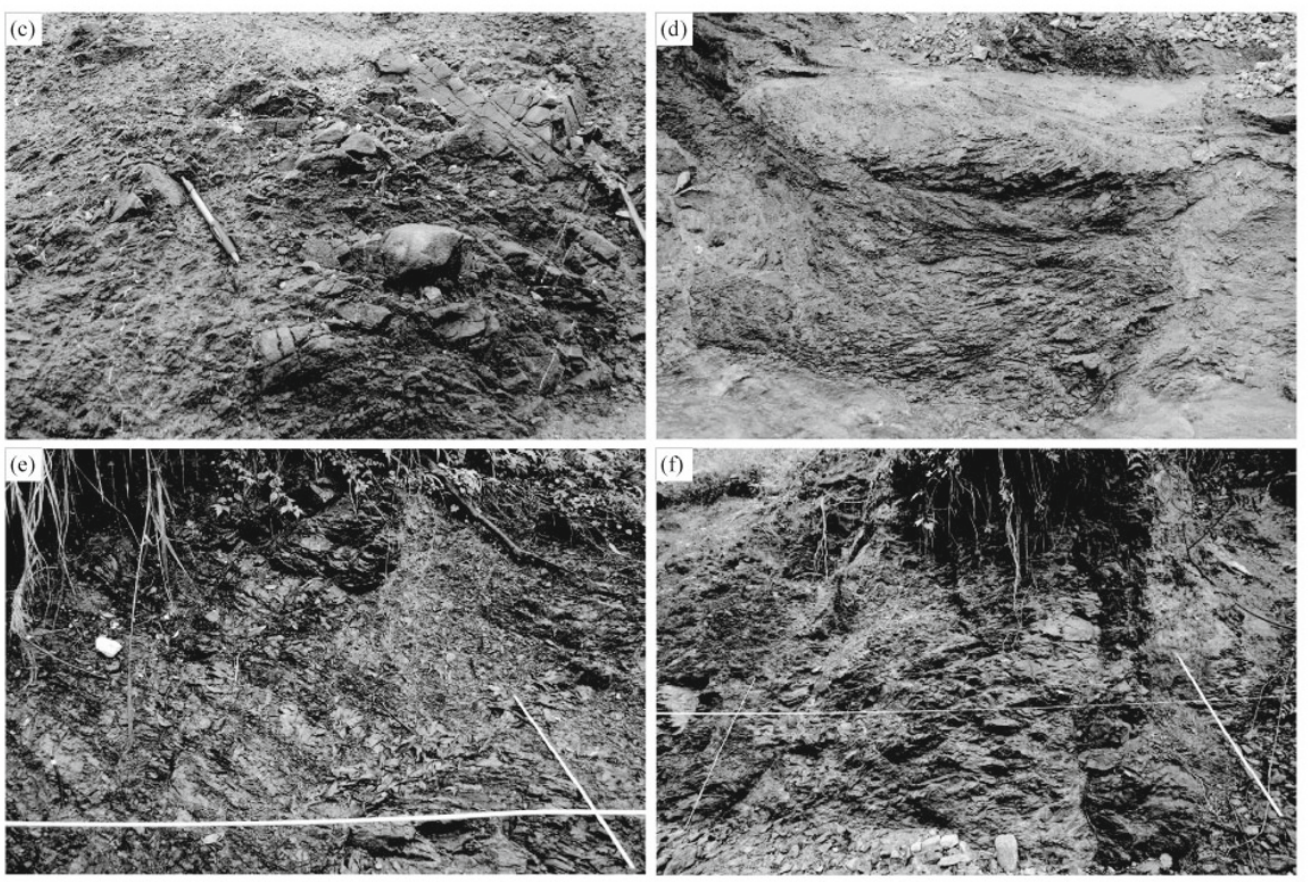

Figure 7 Fault breccias on the eastern bank of the Baisha River. (a) An overview photograph and (b) its sketch showing fault rock classification. The other photographs show (c) black fault breccia, (d) grayish fine breccia, and (e) and (f) weakly-deformed fault breccias, respectively. Positions of (c) to (f) are shown in (b). 
in Figure 3, and we regard this as the margin of the host rock to a fault breccia zone.

Exposures on southeastern bank of Baisha River and classification of fault breccias are shown in Figures $7 \mathrm{a}$ and $7 \mathrm{~b}$, respectively. Black fault breccia is exposed
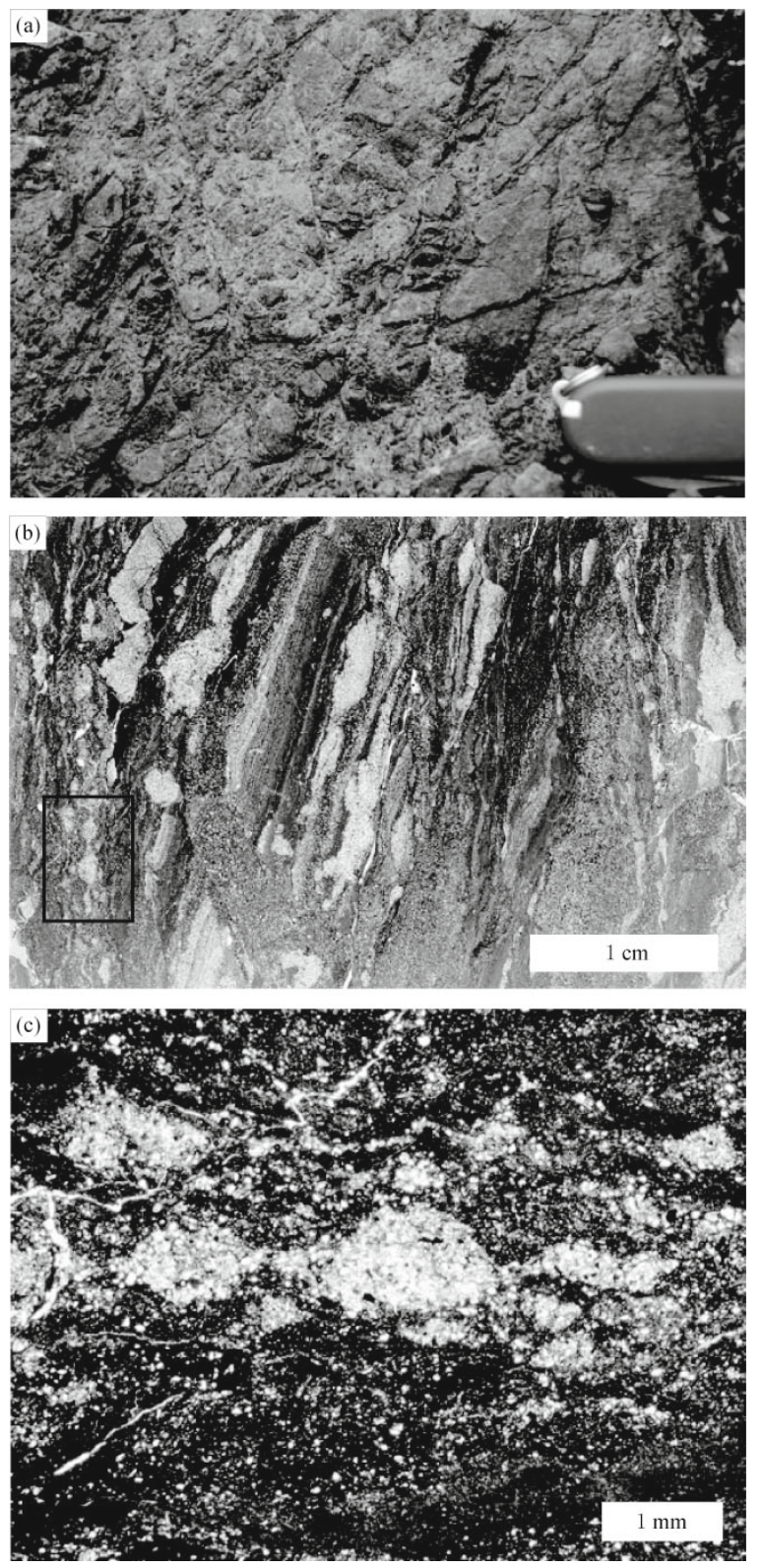

Figure 8 (a) A photograph of black fault breccia at position $H$ in Figure 3. (b) A scanned image of a thin section of the black fault breccia consisting of dark-colored shale and light-colored sandstone. (c) A photomicrograph of black fault breccia on the left side of (b). Original sedimentary structures such as graded bedding and lamina are preserved in (b). The sample for (b) and (c) was collected at position $H$ in Figure 3. close to coseismic fault and consists of broken clasts of various sizes and finely comminuted matrix (Figures 7c and 8a). A photomicrograph in Figure 8b indicates that clasts preserve original sedimentary structures such as graded bedding and lamina even though they were
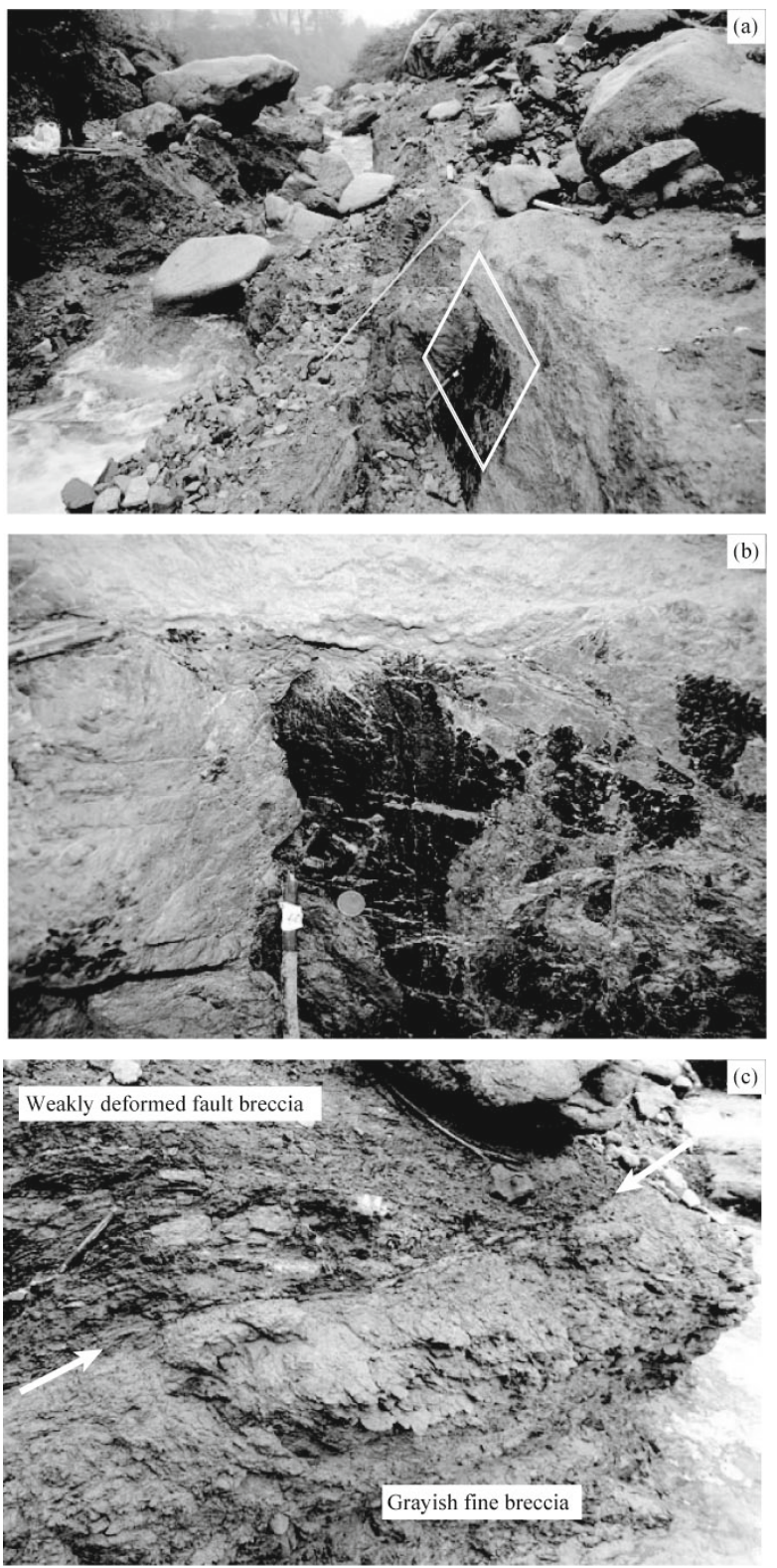

Figure 9 (a) A photograph showing black gouge separating grayish fine breccia to the left and grayish breccia to the right at a position near $F$ in Figure 3. The photograph was taken to SSW direction towards the coseismic fault. (b) A close-up photograph showing the black gouge in (a) with nearly vertical striations. (c) A photograph of black gouge between weakly deformed fault breccia (top side) and grayish fine breccia (bottom side) at position $G$ in Figures 3 and $7 \mathrm{~b}$. 
deformed. Those sedimentary structures are not preserved in deformed portions consisting of clasts and fine matrix (Figure 8c). Grayish fine breccia in Figure $7 \mathrm{~d}$ contains finer clasts and is more deformed than the black fault breccia. Grayish breccia on the west bank in Figure 3 is similar to grayish fine breccia except that clasts are coarser grained than the latter. Wide areas on east bank and cliffs consist of weakly deformed fault breccia such as those in Figures $7 \mathrm{e}$ and $7 \mathrm{f}$ for which clast-matrix structures are developed, but original bedding planes are preserved (e.g., strike and dip at one point is $\mathrm{N} 57^{\circ} \mathrm{E}$
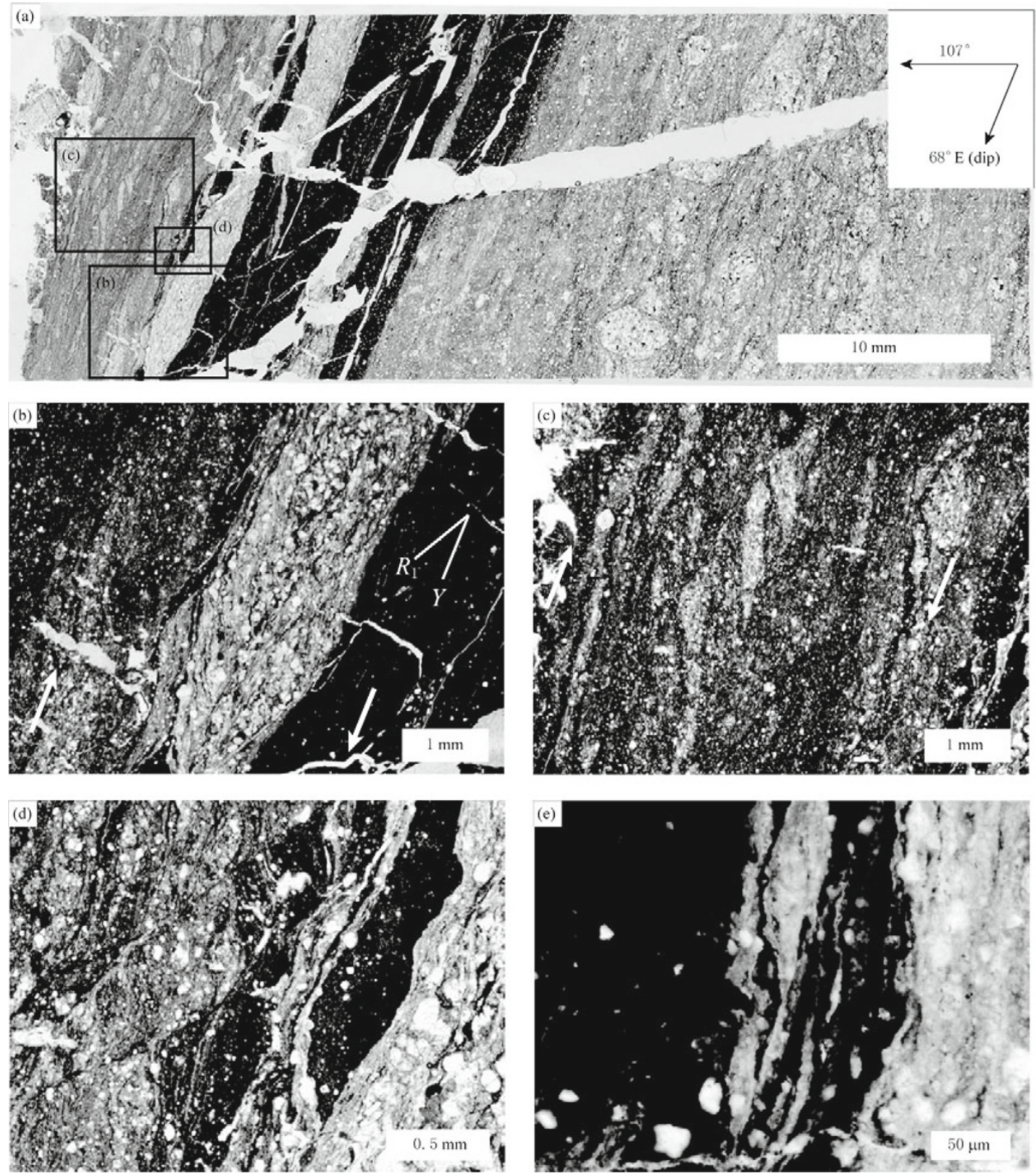

Figure 10 Photomicrographs of black gouge collected at position $G$ in Figure 3, showing textural evidence of reverse fault motion. (a) A scanned image of a thin section of black gouge; thin section is made normal to the gouge and parallel to the striation of gouge with orientation given on the upper-right corner (strike and dip of gouge: $\mathrm{N} 17^{\circ} \mathrm{E}$ and $68^{\circ} \mathrm{SE}$ ). Other photomicrographs taken under plane-polarized light show (b) $R_{1}$ Riedel shear, (c) duplex-like structures in the center, (d) complex wavy textures of dark-colored gouge, and (e) an enlarged view of black gouge/pelitic gouge boundary with wavy textures. Black gouge contains amorphous carbon. 
and $84^{\circ} \mathrm{SE}$, Figure 3 ).

Classification of those fault breccias was done conventionally in the field. However, at most places those fault-breccia zones were bounded by peculiar black gouge shown in Figure 9. It is very black in color and several to a few tens of millimeters in thickness with orientation of NNE-SSW with high dipping angles (see orientation data in Figure 3). Their orientation deviates from that of coseismic fault of Wenchuan earthquake by a few tens of degrees. This black layer is much darker in color than the clayey fault gouge in the fault core, but the black layer has to be called "fault gouge" because it is a fine-grained incohesive fault rock displacing fault breccia zones. Vertical striations are recognized locally (Figure 9b).

A scanned image of a thin section in Figure 10a exhibits that black gouge is an opaque layer and separates grayish fault breccia to the right and foliated pelitic fault gouge and breccia to the left. Black color must be due to amorphous carbon contained in the gouge (see next section). The boundary between black gouge and foliated fault gouge appears to be concordant, suggesting their contemporaneous formation. Foliation on the right side of Figure 10a is far more pervasive and uniform than that in the weakly-foliated clayey fault gouge in the fault core (cf. Figures $5 \mathrm{c}$ and $5 \mathrm{~d}$ ). Thus black gouge and some fault rocks may be of earlier deformation structures than those associated with recent movement of Longmenshan fault system.

The other boundary zone exhibits rich structures as shown in other photomicrographs in Figure 10, taken under plane-polarized light. $R_{1}$ Riedel shears and duplex-like structures are formed in Figures $10 \mathrm{~b}$ and $10 \mathrm{c}$, suggesting reverse fault motion in view of the orientation of thin section. A dark-colored layer appears to have displaced and overlapped while undergoing complex deformation due to a step at the boundary that can act as an obstacle for reverse fault motion (Figure 10d). More complex stacking is recognized in Figure 10e. Note also that shear bands are developed in Figure 10d (cf. Passchier and Trouw, 2005), indicating reverse fault motion too.

\section{X-ray diffraction analysis of fault rocks}

Constituent minerals, clay minerals in particular, affect mechanical properties of fault rocks and hence we performed X-ray diffraction (XRD) analysis to determine mineral composition. Three types of samples were analyzed to identify minerals from overlapping diffraction peaks, using clayey fault gouge next to the coseismic fault (gouge 1 in Figure 5a), wholerock sample powder, elutriated sample, and residue after acid treating. These samples were used for identification of the main rock-forming minerals, clay minerals and insoluble minerals, respectively. More specifically, air-dried sample was ground in an alumina mortar to make whole-rock powder. For the clay mineral analysis, rock powder was elutriated in water column and supernatant fluid with suspended powder was mounted on a slide glass to dry water and made an oriented specimen. Ethylene glycol treated and thermally treated oriented samples were also X-rayed to identify clay minerals (e.g., Moore and Reynolds, 1997). Additionally, we treated sample powder with mixed acid of hydrochloric acid (6M) and hydrofluoric acid $(6 \mathrm{M})$ and collected insoluble minerals. The XRD analysis was done by using a Rigaku Corporation multiflex at Hiroshima University with the following conditions: anode is $\mathrm{Cu}$, acceleration voltage is $40 \mathrm{kV}$, current is $40 \mathrm{~mA}$, step size is $0.01^{\circ}$, and scan speed is $1^{\circ} / \mathrm{min}$. Insoluble residual samples were held on a non-reflecting monocrystalline silicon sample holder and other samples were held on glass sample holders. The mineral composition was analyzed semiquantitatively with ICDD (International Centre for Diffraction Data) profile using a software attached to the XRD machine.

XRD profile in Figure 11a yields mineral compositions of clayey fault gouge in fault core as quartz $(63.8 \%)$, chlorite $(6.4 \%)$, dolomite $(5.5 \%)$, illite $(4.6 \%)$, albite $(3.4 \%)$, and other minerals $(16.3 \%$, discussed in detail below). Likewise, Figure 11c gives composition of black gouge as quartz (75.4\%), dolomite (7.8\%), illite $(4.6 \%)$, chlorite $(4.5 \%)$, and other minerals $(7.7 \%)$. Thus XRD analyses of the oriented samples, ethylene glycol treated samples and thermally treated oriented samples all show that the main clay minerals are illite and chlorite (Figures 11b and 11d). We could not confirm presence of smectite even after ethylene glycol and heat treatments (see curves 2 and 3 in Figures 11b and 11d). Relative abundance of clay minerals could not be determined since oriented specimens are used for XRD analyses.

Figure 12 shows the XRD profiles of the insoluble residual materials for gouge sample 1 collected closest to coseismic fault (1), for fault gouge sample 2 collected at about $40 \mathrm{~cm}$ away from the margin of fault core (2), 

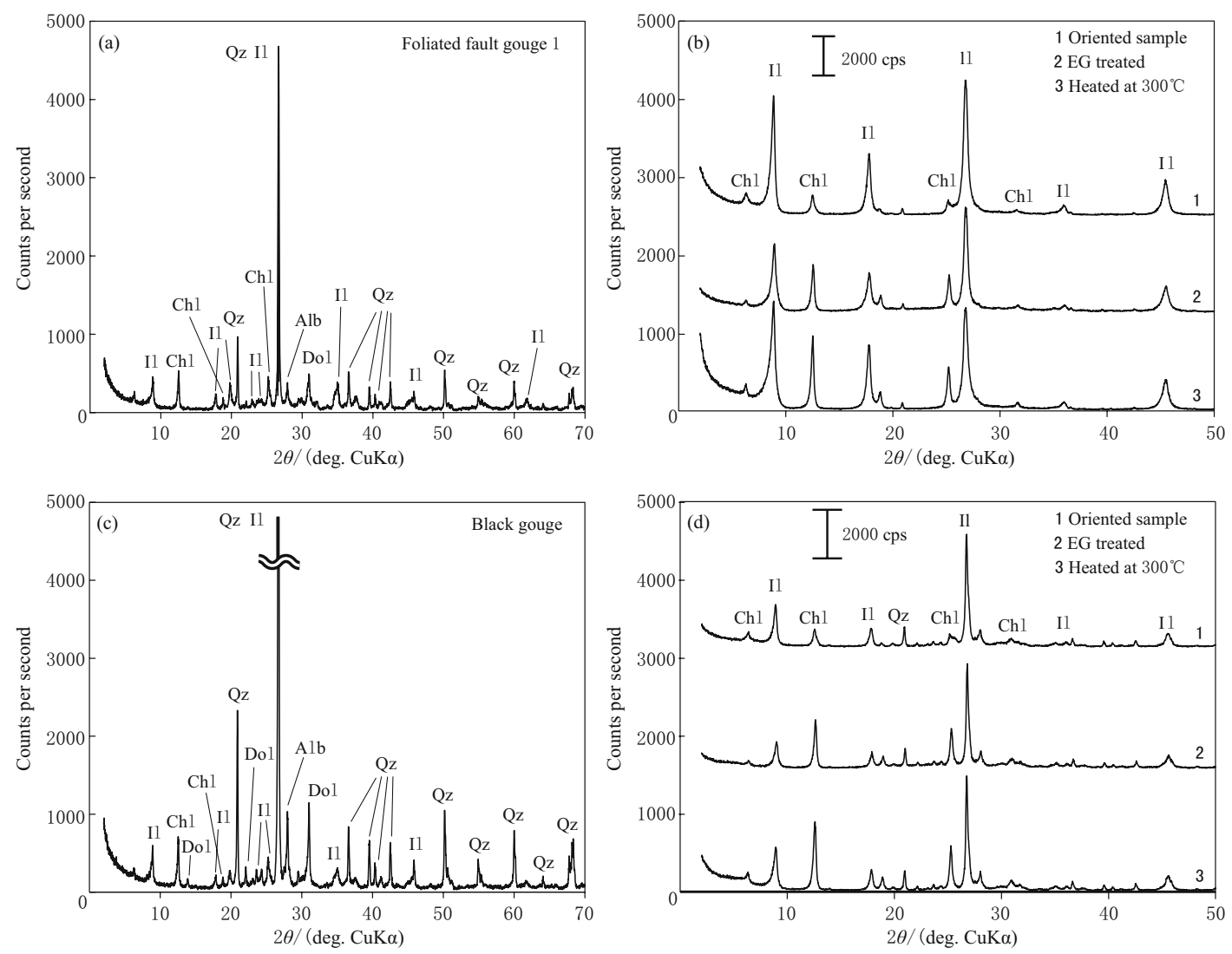

Figure 11 X-ray diffraction (XRD) profiles for fault gouge next to the coseismic fault (a, b), and for black gouge (c, d). XRD profiles in (a) and (c) are for bulk samples, whereas those in (b) and (d) are for elutriated samples for clay mineral analysis. Fault gouge sample 1 was collected at the open-circle point in Figure $5 \mathrm{a}$ (about $10 \mathrm{~cm}$ from the edge of gouge), and the same black gouge for making the thin section in previous figure was used for the analysis. Mineral abbreviations: Qz — quartz, Alb — albite, Dol — dolomite, Il — illite, Chl — chlorite.

and for black gouge sample (3), respectively. Recovered materials after the acid treatment were $16.3 \mathrm{wt} \%$ for fault gouge sample 1, $29.5 \mathrm{wt} \%$ for gouge sample 2 , and $7.7 \mathrm{wt} \%$ for black gouge. Characteristic broad peak between 20 to 30 degrees corresponds to the reflection peak of amorphous carbon and are recognized for all three samples. The other minor sharp peaks correspond to rutile, anatase, zircon, graphite and pyrite. Only gouge sample 1, closest to the coseismic fault, exhibits clear graphite peak in Figure 12.

\section{Conclusions and discussion}

This work was started as a part of integrated fault and earthquake project of Institute of Geology, CEA, trying to reproduce Wenchuan earthquake by modeling based on measured frictional and transport properties of Longmenshan fault system. We have described internal structures of Beichuan fault, the major fault in Longmenshan fault system, that caused the disastrous Wenchuan earthquake, at an outcrop in Hongkou. Immediate application of this work is the comparison with results from the WFSD-1 and WFSD-2 drilling being conducted at places only few to several hundred of meters north from the outcrop. Present work will be extended to many other fault outcrops along the surface ruptures in order to understand along-fault heterogeneity of fault zones and to exhume faults to see how fault zone changes towards greater depths. Longmenshan area is a good place to study deeper fault zones because beautiful mylonite zones are exposed here due to rapid uplifting (e.g., Xu et al., 2008).

The major outcomes of present work can be summarized as follows:

1) The hanging wall side of Beichuan fault zone is 30-40 m wide (no exposure of the downthrown side). The fault zone consists of weakly-foliated clayey fault gouge (ca. $1 \mathrm{~m}$ in width) and several fault breccia 


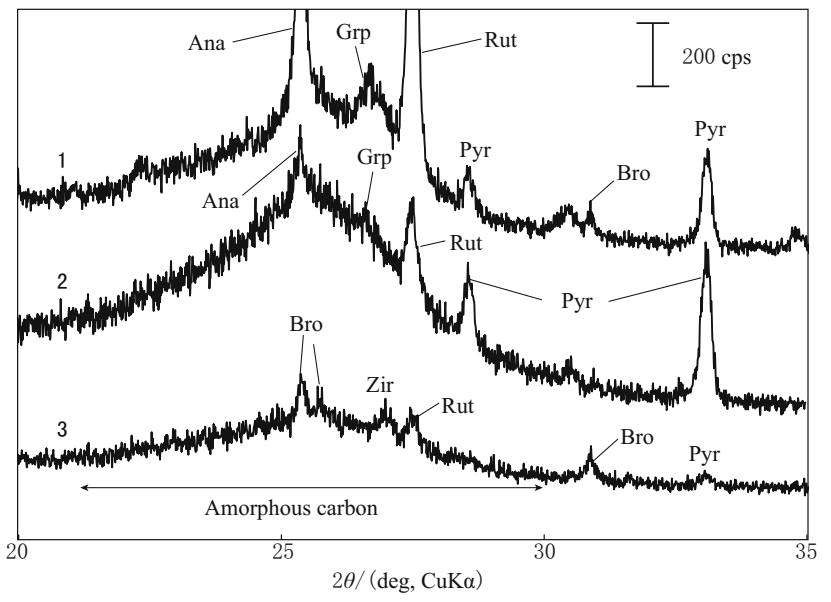

Figure 12 XRD profiles of nondissolved residue of the fault gouge sample 1 collected about $10 \mathrm{~cm}$ away from the gouge margin on the coseismic fault side (1), fault gouge sample 2 collected about $40 \mathrm{~cm}$ away from the gouge margin (2), and black gouge (3). Broad peaks between 20 and 30 degrees correspond to the amorphous graphite and the other sharp peaks are identified as rutile (Rut), anatase (Ana), brookite (Bro), graphite (Grp), zircon (Zir) and pyrite (Pyr). Graphite (002) reflection peak is recognized only in fault gouge 1 close to the coseismic fault (see its location in Figure 5a).

zones often bounded by small-scale faults containing thin black gouge of several to a few tens of millimeters in width. Strike and dip of the coseismic fault associated with the Wenchuan earthquake at this outcrop is N30 $40^{\circ} \mathrm{E}$ and $75^{\circ}-80^{\circ} \mathrm{NW}$ (data for surface rupture and foliation in gouge). Small-scale faults are steeply dipping faults trending in the NNE-SSW direction, which are probably of older origin than currently active Beichuan fault, in view of their more pervasive and uniformly developed foliation as compared to that of weakly-foliated clayey fault gouge, associated with the Wenchuan earthquake fault.

2) The slipping-zone that accommodated fault motion during the Wenchuan earthquake is 10 to $20 \mathrm{~mm}$ in width on the hanging wall side judged from the slickenside surface of coseismic fault. This is an important constraint for estimating the coseismic temperature rise responsible for the activation of dynamic weakening mechanism of faults (e.g. thermal pressurization). Overlapping structures of striations on slickenside surface suggest that seismic slip at a given time occurred in even narrower zone of a few to several millimeters, so that localization of deformation must have occurred within a slipping zone during coseismic fault motion.

3) Fault gouge contains illite and chlorite as clay minerals which will be important minerals that affect frictional and transport properties of fault zone. We could not confirm the presence of smectite which has potential to reduce friction and permeability.

4) Fault breccia zones are mostly separated by thin black gouge containing amorphous carbon. Clayey fault gouge next to coseismic fault also contains amorphous carbon, and a small amount of graphite was recognized near the coseismic fault. Carbon and graphite may affect mechanical properties of faults. Graphite may have formed due to seismic fault motion.

Conclusion (1) above is a summary of Beichuan fault zone on the hanging-wall side, its scale and internal structures. The last statement in (1) may warrant a comment. Small-scale faults containing black gouge and separating fault breccia zones are in the orientation of $P$ Riedel shears (e.g., Bartlett et al., 1981) with respect to the right-lateral movement recognized for this fault (compare the orientations of small-scale faults and coseismic fault in Figure 3). However, striation on black gouge is in dip direction (Figure 9b) and does not indicate predominantly strike-slip fault motion. Moreover, black gouge and adjacent fault gouge is more lithified with more uniform and pervasive foliation (Figure 10) than that of the main clayey fault gouge zone (Figure $5)$. We thus have an impression that a slightly older fault zone, composed of fault breccia zones separated by small-scale fault zones, is cut by a currently active portion of Beichuan fault at a small angle.

Conclusion (2) has an important implication for thermal pressurization in a fault zone that can weaken a fault dramatically by building up pore pressure due to frictional heating (Sibson, 1973; Lachenbruch, 1980; Mase and Smith, 1987). This mechanism received attention partly because thermal pressurization yields slip-weakening distance and fracture energy on the same order as seismically determined values (Wibberley and Shimamoto, 2005; Noda and Shimamoto, 2005; Rice, 2006). Measuring permeability and storage capacity is needed to evaluate thermal pressurization, and permeability measurement has started at an outcrop of Beichuan fault (Yang et al., 2010). One uncertainty is the width of the slipping zone over which frictional work is dissipated, as this can affect how rapidly a fault loses its strength with slip (e.g., Wibberly and Shimamoto, 2005; Noda and Shimamoto, 2005). A slipping-zone width of 10-20 mm, observed at the studied outcrop, poses an important constraint for thermal-pressurization behavior of Be ichuan fault. An important and exciting implication of overlapping striations in Figure 2c is that 
the slipping zone can become even narrower during slip than the bulk slipping zone. Indeed, a recent analysis of thermal pressurization (Platt et al., 2010) demonstrates that localization of deformation can occur during thermal pressurization process. More involved analyses of thermal pressurization may be needed than those assuming fixed slipping-zone width.

Lin et al. (2010) reported fault-zone structures and principal slip zone of a few millimeters in width during Wenchuan earthquake integrating data from three outcrops and one trench, including the Hongkou outcrop described here. Our result is consistent with theirs with respect to the slip-zone width (cf. a comprehensive review of Sibson, 2003). As for the description of the fault zone as a whole, however, there are considerable differences between Lin et al. (2010) and present paper partly due to different usage of terminology and limited exposures. They concluded that fault gouge zone is less than $15 \mathrm{~cm}$ in width and is typically $10-20 \mathrm{~mm}$ wide, that fault breccia zone is less than about $3 \mathrm{~m}$ in width and that damage zone composed of cataclastic rocks including fractures and subsidiary rocks is wider than $5 \mathrm{~m}$. Lin et al. (2010) reported a fault zone in Hongkou in their Figure 4c. This outcrop is probably located between our Figure 4a and the coseismic fault in Figure 2b, so that nearly the same fault zone structures should be shown in their Figure 4c and our Figures 4a and 4b. We could not collect sample from coseismic slip zone and Lin et al. (2010) reported useful data on slipping zones that we could not report here. However, our gouge zone of about $0.7 \mathrm{~m}$ in width is described as foliated fault breccia and fault breccia in their Figure 4c. But we could not find visible clasts by more than $30 \%$ and named it as fault gouge following Sibson's (1977) classification (Figure 5a). The edge of our fault breccia zone is called cataclasite in Lin et al. (2010, see their Figure 4c). Certainly some part of fault breccia zone is lithified and may be called cataclasite (e.g., fault breccia in our Figure 8a) although it is not as hard as typical cataclasite. However, fault breccia zones we showed in Figure 7 are no doubt incohesive fault rocks as a whole although it contains older fault rocks as discussed above. Lin and coworkers probably have not seen the Hongkou outcrop after fault zone was washed away by debris flow. Their paper thus should be read as a paper describing fault core parts of the Beichuan fault zone.

As for clay minerals in fault zone (conclusion (3) above), we could find illite and chlorite. Whereas Li et al. (2010b) and Si et al. (2010) reported a black gouge zone at a depth of about $590 \mathrm{~m}$ in WFSD-1, charac- terized by high smectite content, low contents of illite, chlorite and kaolinite, and high magnetic susceptibility. A black fault gouge with similar mineralogical composition as reported by Li et al. (2010b) and Si et al. (2010) was not recognized at Hongkou outcrop, probably either because the thin slipping zone, formed at depths, has been eroded away when fault zone thrust over surface sediments or because such gouge could not form at near surface conditions. However, high-velocity friction experiments in the last several years have demonstrated that mineral decomposition can occur during seismic fault motion due to frictional heating (see Togo et al., 2011). Thus, difference in fault gouge between surface outcrops and drill cores will delineate possible changes in fault zone during seismic fault motion.

Carbonaceous materials in fault zones have received little attention till recently when Oohashi and Kobayashi (2008) reported faults containing carbonaceous material and pointed out the importance of graphite as a lubricating agent of fault. Moreover, Oohashi et al. (2011) demonstrated by experiments that amorphous carbon can transform to graphite during seismic fault motion at bulk pressure and temperature conditions much smaller than previously thought for graphite formation. Our conclusion (4) above is exciting since graphite near the coseismic fault might have formed at shallow conditions due to seismic fault motion as demonstrated by high-velocity friction experiments by Oohashi et al. (2011). We plan to perform high-velocity friction experiments to produce graphite from carbonaceous materials using Beichuan fault gouge soon. This can be a demonstration that what might have happened in nature can be reproduced by high-velocity experiments in laboratory, thereby strengthening the applicability of laboratory experiments to nature.

Acknowledgements We thank two anonymous reviewers for giving many useful comments and suggestions. We also thank A. Tsutsumi who read an early version of our manuscript and suggested several improvements. Present work was supported by State Key Laboratory of Earthquake Dynamics (project No. LED2008A03) and Wenchuan Earthquake Fault Scientific Drilling Project (WFSD), by a Grant-in-Aid for JSPS Fellows (No. 201007605) to the first author (T. Togo), and by a 2009 Grant-in-Aid of Fukada Geological Institute.

\section{References}

Bartlett W L, Friedman M and Logan J M (1981). Experi- 
mental folding and faulting of rocks under confining pressure, part IX, Wrench faults in limestone layers. Tectonophysics 79: 255-277.

Brodsky E, Ma K F, Mori J and Saffer D M (2009). Rapid response fault drilling: past, present and future. Report of the ICDP/SCEC International Workshop of Rapid Response Fault Drilling. Tokyo, Japan, Nov. 17-19, 2008.

Burchfiel B C, Royden L H, van der Hilst R D, Hager B H, Chen Z, King R W, Li C, Lu J, Yao H and Kirby E (2008). A geological and geophysical context for the Wenchuan earthquake of 12 May 2008, Sichuan, People's Republic of China. GSA Today 17(7): 4-11, doi:10.1130/GSATG18A.1.

Fu B H, Shi P L, Guo H D, Okuyama S, Ninomiya Y and Wright S (2011). Surface deformation related to the 2008 Wenchuan earthquake, and mountain building of the Longmen Shan, eastern Tibetan Plateau. J Asian Earth Sci 40: 805-824.

Han L, Zhou Y, Chen J, Ma S, Yang X, He C and Dang J (2010). Structural characters of co-seismic fault gouge in bed rocks during the Wenchuan earthquake. Quaternary Sciences 30: 745-758, doi:10.3969/j.issn.10027410.2010.04.10 (in Chinese with English abstract).

He H, Sun Z, Wei Z, Dong S, Gao X, Wang S and Wang J (2008). Rupture of the $M_{\mathrm{S}} 8.0$ earthquake along Baishahe River. Seismology and Geology 30: 658-673 (in Chinese with English abstract).

Klinger Y, Ji C, Shen Z K and Bakun W H eds. (2010a). The special issue on the 2008 Wenchuan, China, earthquake. Bull Seismol Soc Am 100: 2353-2 872.

Klinger Y, Ji C, Shen Z K and Bakun W H (2010b). Introduction to the special issue on the 2008 Wenchuan, China, earthquake. Bull Seismol Soc Am 100: $2353-2356$, doi:10.1785/0120100172.

Lachenbruch A H (1980). Frictional heating, fluid pressure, and the resistance to fault motion. $J$ Geophys Res 85: 6097-6 112.

Li H B, Si J L, Pei J L, Fu X F, Wang Z X, Hou L W, Li N, Wu F Y and Pan J W (2010a). Investigating the surface rupture process of the Wenchuan earthquake $\left(M_{\mathrm{S}} 8.0\right)$. Quaternary Sciences 30: 677-698 (in Chinese with English abstract).

Li H B, Xu Z, Si J, Pei J, Li T, Huang Y and Wang $\mathrm{H}$ (2010b). Characteristics of the fault-related rocks, fault zone structures and the principal slip zone of the Wenchuan earthquake in WFSD drilling cores. American Geophysical Union, Fall Annual Meeting. San Francisco, T53E-02, Dec. 13-17, 2010.

Lin A, Ren Z, Jia D and Wu X (2009). Co-seismic thrusting rupture and slip distribution produced by the 2008 $M_{\mathrm{W}} 7.9$ Wenchuan earthquake, China. Tectonophysics 471: 203-215, doi:10.1016/j.tecto.2009.02.014.

Lin A, Ren Z and Kumahara Y (2010). Structural analysis of the coseismic shear zone of the $2008 M_{\mathrm{W}} 7.9$
Wenchuan earthquake, China. J Struct Geol 32: 781791, doi:10.1016/j.jsg.2010.05.004.

Liu-Zeng J, Wen L, Sun J, Zhang Z, Hu G, Xing X, Zeng L and Xu Q (2010). Surfacial slip and rupture geometry on the Beichuan fault near Hongkou during the $M_{\mathrm{W}} 7.9$ Wenchuan earthquake, China. Bull Seismol Soc Am 100: 2615-2 650, doi:10.1785/0120090316.

Liu-Zeng J, Zhang Z, Wen L, Tapponnier P, Sun J, Xing X, Hu G, Xu Q, Zeng L, Ding L, Ji C, Hudnut K W and van der Woerd J (2009). Co-seismic ruptures of the 12 May 2008, $M_{\mathrm{S}} 8.0$ Wenchuan earthquake, Sichuan: East-west crustal shortening on oblique, parallel thrusts along the eastern edge of Tibet. Earth Planet Sci Lett 286: 355370.

Ma K F, Brodsky E E, Mori J, Ji C, Song T A and Kanamori $\mathrm{H}$ (2003). Evidence for fault lubrication during the 1999 Chi-Chi, Tawan, earthquake $\left(M_{\mathrm{W}} 7.6\right)$. J Geophys Res 30: 1 244, doi:10.1029/2002GL015380.

Ma K F, Tanaka H, Song S R, Wang C Y, Hung J H, Tsai Y B, Mori J, Song Y F, Yeh E C, Soh W, Sone H, Kuo L W and Wu H Y (2006). Slip zone and energetic of a large earthquake from the Taiwan Chelungpu-fault Drilling Project. Nature 444: 473-476, doi:10.1038/nature05253.

Mase C W and Smith L (1987). Effects of frictional heating on the thermal, hydrologic, and mechanical response of a fault. J Geophys Res 92: 6 249-6 272.

Moore D and Reynolds R C Jr (1997). X-Ray Diffraction and the Identification and Analysis of Clay Minerals. 2nd ed. Oxford University Press, New York, 400pp.

Noda H and Lapusta N (2009). Earthquake cycle simulation with a rate-, temperature- and state-dependent friction law (abstract). Japan Geoscience Union Meeting 2009. J169-001, Chiba, Japan, May 16-21, 2009.

Noda H and Shimamoto T (2005). Thermal pressurization and slip-weakening distance of a fault: an example of the Hanaore fault, Southwest Japan. Bull Seismol Soc Am 95: 1 224-1 233, doi:10.1785/0120040089.

Oohashi K, Hirose T and Shimamoto T (2011). Shearinduced graphitization of carbonaceous materials during seismic fault motion: experiments and possible implications for fault mechanics. J Struct Geol (in press).

Oohashi K and Kobayashi K (2008). Fault geometry and paleo-movement of the central part of the Ushikubi fault, northern central Japan. J Geol Soc Japan 114: 16-30 (in Japanese with English abstract).

Oshiman N, Shimamoto T, Takemura K and Wibberley C A J eds. (2001). Thematic issue: Nojima fault zone probe. Island Arc 10: 195-505.

Passchier C W and Trouw R A J (2005). Microtectonics. Second edition. Springer, Heidelberg, 289pp.

Platt J D, Rice J R and Rudnick J W (2010). Strain localization within a fluid-saturated fault gouge layer during seismic shear. American Geophysical Union, Fall Annual Meeting. San Francisco, T31D-03, Dec.13-17, 2010. 
Rice J R (2006). Heating and weakening of faults during earthquake slip. $J$ Geophys Res 111: B05311, doi:10.1029/2005JB004006.

Shen Z K, Sun J, Zhang P, Wan Y, Wang M, Burgmann R, Zeng Y, Gan W, Liao H and Wang Q (2009). Slip maxima at fault junctions and rupturing of barriers during the 2008 Wenchuan earthquake. Nature Geoscience 2: 718-724, doi:10.1038/NGEO636.

Si J, Li H, Song S, Kuo L, Pei J and Wang H (2010). Clay mineral anomalies in WFSD drilling core and surface fault rocks and their significnces. American Geophysical Union, Fall Annual Meeting. San Francisco, T51B-2044, Dec. 13-17, 2010.

Sibson R H (1973). Interactions between temperature and pore fluid pressure during an earthquake faulting and a mechanism for partial or total stress relief. Nature 243: 66-68.

Sibson R H (1977). Fault rocks and fault mechanisms. J Geol Soc London 133: 191-213.

Sibson R H (2003). Thickness of the seismic slip zone. Bull Seismol Soc Am 93: 1169-1 178.

Sone H and Shimamoto T (2009). Frictional resistance of faults during accelerating and decelerating earthquake slip. Nature Geosciences 2: 705-708, doi:10.1038/ bgei637 Letter.

Song S R, Wang C Y, Hung J H and Ma K F eds. (2007). The special issue on Taiwan Chelungpu-fault Drilling Project (TCDP). Terr Atmos Ocean Sci 18: 129-373.

Tanikawa W and Shimamoto T (2009). Frictional and transport properties of the Chelungpu fault from shallow borehole data and their correlation with seismic behavior during the 1999 Chi-Chi earthquake. J Geophys Res 114: B01402, doi:10.1029/2008JB005750.

Togo T, Shimamoto T, Ma S L and Hirose T (2011). Highvelocity frictional behavior of Longmenshan fault gouge from Hongkou outcrop, and its implications for dynamic weakening of fault during the 2008 Wenchuan earth- quake. Earthquake Science 23(3): 267-281.

Wen L, Sun J, Zhang Z, Hu G, Xing X, Zeng L and $\mathrm{Xu}$ Q (2010). Surficial slip and rupture geometry on the Beichuan fault near Hongkou during the $M_{\mathrm{W}} 7.9$ Wenchuan earthquake, China. Bull Seismol Soc Am 100: 2615-2 650, doi:10.1785/0120090316.

Wibberley C A J and Shimamoto T (2005). Earthquake slip weakening and asperities explained by thermal pressurization. Nature 436: 689-692, doi:10.1038/nature03901.

$\mathrm{Xu}$ X, Wen X, Yu G, Chen G, Klinger Y, Hubbard J and Shaw J (2009). Coseismic reverse- and oblique-slip faulting generated by the $2008 M_{\mathrm{W}} 7.9$ Wenchuan earthquake, China. Geology 37: 515-518, doi:10.1130/G25462A.1.

Xu C, Liu Y, Wen Y and Wang R (2010). Coseismic slip distribution of the $2008 M_{\mathrm{W}} 7.9$ Wenchuan earthquake from joint inversion of GPS and InSAR data. Bull Seismol Soc Am 100: 2 736-2 749, doi:10.1785/0120090253.

$\mathrm{Xu} \mathrm{Z}$ and $\mathrm{Li} \mathrm{H}$ (2010). New results from the Wenchuan Earthquake Fault Scientific Drilling Project (WFSD). American Geophysical Union, Fall Annual Meeting. San Francisco, T53E-01, Dec. 13-17, 2010.

Xu Z, Ji S, Li H, Hou L, Fu X and Cai Z (2008). Uplift of the Longmen Shan range and the Wenchuan earthquake. Episodes 31(3): 291-301.

Yin A (2010). A special issue on the great 12 May 2008 Wenchuan earthquake $\left(M_{\mathrm{W}} 7.9\right)$ : Observations and unanswered questions. Tectonophysics 491: 1-9, doi:10.1016/j.tecto.2010.05.019.

Yin A, Freymueller J T, Keller G R, Ni S and Song S eds. (2010). Great 12 May 2008 Wenchuan Earthquake $\left(M_{\mathrm{W}} 7.9\right)$, China. Special issue. Tectonophysics 491: 1274.

Yang X, Chen J and Ma S (2010). Permeability and grain size distribution of Wenchuan earthquake fault rocks. American Geophysical Union, Fall Annual Meeting. San Francisco, T51B-2042, Dec. 13-17, 2010. 